\title{
BMJ Effect of occupation on risk of developing Open Ms: an insurance cohort study
}

\author{
Henrik Horwitz, ${ }^{1}$ Birgitte Ahlgren, ${ }^{2}$ Elisabeth Nærum $^{3}$
}

To cite: Horwitz $\mathrm{H}$, Ahlgren B, Nærum E. Effect of occupation on risk of developing MS: an insurance cohort study. BMJ Open 2013;3:e002894. doi:10.1136/ bmjopen-2013-002894

- Prepublication history for this paper is available online. To view these files please visit the journal online (http://dx.doi.org/10.1136/ bmjopen-2013-002894).

Received 18 March 2013 Revised 14 May 2013 Accepted 15 May 2013

This final article is available for use under the terms of the Creative Commons Attribution Non-Commercial 2.0 Licence; see http://bmjopen.bmj.com

\footnotetext{
${ }^{1}$ Department of Pharmacology, Bispebjerg Hospital, University of Copenhagen, Copenhagen, Denmark

${ }^{2}$ Master of Science in Finance and Strategic Management, PensionDanmark, Copenhagen, Denmark ${ }^{3}$ Actuary, ATP, Hillerød, Denmark
}

Correspondence to Dr Henrik Horwitz; henrik_horwitz@hotmail.com

\section{ABSTRACT}

Objective: The aim of this study was to estimate the occupational risks in relation to multiple sclerosis (MS). The immediate background for this research was our finding that there had been a high number of critical illness insurance claims by patients diagnosed with MS within the agricultural segment of a Danish pension fund.

Design: An open insurance cohort. All payouts for the critical illness insurance from 2002 to 2011 were continuously registered.

Settings: PensionDanmark; one of Denmark's largest pension funds.

Participants: PensionDanmark insures more than 300000 members of the Danish Confederation of Trade Unions against critical illness. All members are insured, and all policies are identical. The total exposure is 3.3 million person-years.

Primary outcome measures: The incidence of MS. Results: During the 10-year period, 389 persons were diagnosed with MS. The crude incidence rate for men was $10.2 / 100000$; the corresponding figure for women was 16.1/100 000. We found signs of an overall effect of occupation on the risk of developing MS, and the high frequency found within the agricultural segment was attributed to dairy operators, who had an incidence of MS 2.0 times higher than the rest of the study's population ( $95 \% \mathrm{Cl}=1.2$ to 3.0$)$.

Conclusions: Our results indicate some occupational risk factors in MS, and this should be investigated further.

\section{INTRODUCTION}

Thirty years ago, the first critical illness insurance policy was put on the market in South Africa. The originator of the project was Marius Barnard, a South African heart surgeon and brother of Christiaan Barnard, the first person to carry out a successful heart transplant. The product quickly gained a strong foothold in South Africa and rapidly spread to other countries. The critical illness insurance is paid out as a lump sum when the policyholder is diagnosed with a critical illness, and was originally meant to be an alternative to an ordinary life or disability insurance, which is paid out to family

\section{ARTICLE SUMMARY}

Article focus

- To investigate the occupational risks of multiple sclerosis (MS) through its incidence among critical illness insurance policy holders.

Key message

- Dairy operators had twice the risk of developing MS.

Strengths and limitations of this study

- The large sample size of 3.3 million person years, and valid data on occupational groups. Furthermore, all MS diagnoses were confirmed by specialists in neurology.

- We were only able to adjust our estimates for age and gender differences.

members after the death of the policy holder or when that person's working ability is severely impaired. This makes the critical illness insurance an excellent epidemiological tool, since it only covers incident cases. ${ }^{1}$ In this article, we used the number of payments of claims due to multiple sclerosis (MS) to estimate the occupational risks associated with the disease.

PensionDanmark insures more than 300000 Danes against critical illness. The policy holders come from all of the sectors represented by the Danish Confederation of Trade Unions (LO) and represent many different occupational groups, for example, construction workers, drivers and industrial workers. All employed Danes have a mandatory occupational pension, and in PensionDanmark, the critical illness insurance is a part of all pension schemes. Furthermore, all policies are identical.

In 2006, we noted an uneven distribution of payments due to MS, with the highest frequencies within the agricultural segment of the pension fund, which comprises dairy workers, gardeners and a small number of agricultural assistants; a group that otherwise had the lowest incidence of critical illness in general. Publications on occupational risks 
and MS have mostly focused on exposure to organic solvents, and the findings have been inconsistent. ${ }^{2} 3$ Other studies have shown that the risk of dying of MS is inversely correlated with occupational UV-light exposure. $^{45}$

We therefore set out to investigate whether there was an increased risk of developing MS among gardeners or dairy workers compared with other occupational groups in PensionDanmark. If gardeners had an excess risk of MS this would go against the observations of vitamin D and sun exposure being protective against MS. ${ }^{6}$ On the other hand, a high incidence rate among dairy workers could support the hypothesis of a link between MS and cow's milk. 78

\section{MATERIALS AND METHODS \\ Numerator \\ Data collection}

A prospective design was used. All payouts for the critical illness insurance from 2002 to 2011 were registered continuously and diagnoses were International Classification of Diseases-10 coded. Furthermore, we had the exact date for the granting of disability pension in each case. In total, 389 payments due to MS had been registered (see table 1).

\section{Denominator}

All active members of PensionDanmark have a critical illness insurance. During the entire period under investigation, all members between the ages of 20-60 were covered, and during the relevant period the age range was gradually extended to provide coverage until the age of 65. Thus, the design was an open insurance cohort, and in total 926005 people had been insured, representing a total of 3.3 million person-years (PYAR). The
PYAR at risk were calculated from the number of members covered on a month-to-month basis. The age and gender distribution is shown in tables 1 and 2 .

\section{Occupational groups}

PensionDanmark operates with the following occupational groups:

- The agricultural segment (9\% of the insured women and $6.7 \%$ of the insured men): gardeners, dairy operators, agricultural workers and tractor traders.

- Construction workers $(8.3 \%$ of the insured women and $48.2 \%$ of the insured men): plumbers, carpenters, bricklayers, electricians, etc.

- Private service $(42 \%$ of the insured women and $10.6 \%$ of the insured men): hairdressers, waiters, hotel and restaurant service personnel and cleaning staff.

- The public sector $(21.8 \%$ of the insured women and $6.1 \%$ of the insured men): cleaning staff, childcare assistants and social workers.

- Trade, transport and industry $(15.1 \%$ of the insured women and $26.9 \%$ of the insured men): long distance drivers, taxi drivers, industrial workers and cashiers.

- Other $(3.8 \%$ of the insured women and $1.6 \%$ of the insured men).

\section{Statistics}

The incidence of MS was calculated in 5-year age intervals. Statistics were applied for the Poisson distribution, and $\mathrm{p}$ values were calculated using likelihood ratio tests. We adjusted for age and gender differences, and tested for interaction between gender and occupation. To investigate biases we examined the prognosis regarding disability pension with Kaplan-Meier statistics and analysed the effect of occupation on general morbidity (insurance claim payments due to all critical illnesses,

Table 1 Policy holders in the period 2002-2011

\begin{tabular}{|c|c|c|c|c|c|}
\hline Occupational group & Gender & PYAR & Individuals & $\begin{array}{l}\text { Average duration of } \\
\text { insurance }(2002-2011)\end{array}$ & $\begin{array}{l}\text { Payments } \\
\text { due to MS }\end{array}$ \\
\hline \multirow[t]{2}{*}{ Construction } & $\mathrm{F}$ & 69074 & 19091 & 3.6 & 12 \\
\hline & $M$ & 1205086 & 271214 & 4.4 & 115 \\
\hline \multicolumn{6}{|c|}{ The agricultural segment } \\
\hline Dairy operators & $\mathrm{F}$ & 29418 & 7964 & 3.7 & 11 \\
\hline Dairy operators & $M$ & 54024 & 14134 & 3.8 & 9 \\
\hline Gardeners & $\mathrm{F}$ & 45256 & 13620 & 3.3 & 8 \\
\hline Gardeners & M & 112624 & 35671 & 3.2 & 13 \\
\hline \multirow[t]{2}{*}{ Private service } & $\mathrm{F}$ & 348200 & 125421 & 2.8 & 41 \\
\hline & M & 264989 & 89417 & 3.0 & 28 \\
\hline \multirow[t]{2}{*}{ Public sector } & $\mathrm{F}$ & 181223 & 50235 & 3.6 & 38 \\
\hline & M & 151098 & 36990 & 4.1 & 19 \\
\hline \multirow{2}{*}{$\begin{array}{l}\text { Trade, transport and } \\
\text { industry }\end{array}$} & $\mathrm{F}$ & 125579 & 45369 & 2.8 & 21 \\
\hline & M & 672835 & 178585 & 3.8 & 67 \\
\hline \multirow[t]{2}{*}{ Others } & $\mathrm{F}$ & 31302 & 15208 & 2.1 & 3 \\
\hline & $\mathrm{M}$ & 38710 & 23086 & 1.7 & 4 \\
\hline Total & 3329418 & 926005 & 3.6 & 389 & \\
\hline
\end{tabular}


Table 2 Age and gender distribution of policy holders in PensionDanmark 2002-2011

\begin{tabular}{llll}
\hline Age & Female & Male & Total \\
\hline $20-24$ & 96639 & 249379 & 346018 \\
$25-29$ & 99202 & 307001 & 406203 \\
$30-34$ & 96328 & 315417 & 411745 \\
$35-39$ & 102896 & 331069 & 433965 \\
$40-44$ & 108774 & 336190 & 444964 \\
$45-49$ & 103141 & 313176 & 416317 \\
$50-54$ & 96607 & 282634 & 379241 \\
$55-59$ & 97070 & 265221 & 362291 \\
$60-64$ & 29395 & 99279 & 128674 \\
Total & $830052(25 \%)$ & $2499366(75 \%)$ & 3329418 \\
\hline
\end{tabular}

eg, myocardial infarction, apoplexy, cancer). Regarding disability pension, the observation time was calculated as the difference between the date of payment of the critical illness insurance and the date of granting of disability pension. Patients were censored when they reached the age of 60 or by the time their disability insurance expired ( 1 year after their last payment to the pension fund). Forty-seven patients were left censored, six patients were already disability pensioners, 12 patients were older than 60 at the time of payment and for 29 patients the disability insurance had expired at the time of payment. All statistics were computed in SAS V.9.2.

\section{Ethics}

It was possible to confine the analysis to PensionDanmark, and it was not necessary to obtain permission from any authority outside PensionDanmarkto use the data.

\section{RESULTS}

During this 10-year period, and a total of 3.3 million PYAR, 389 members were diagnosed with MS. Average age among applicants was 40.6 years (SD 10.5). The crude incidence rate for men was 10.2/100 000 PYAR and for women 16.1/100 000 PYAR ( $\mathrm{p}$ value for gender difference $<0.0001)$.

Figure 1 shows the occupational risks for MS. The highest incidence of MS was found within the agricultural segment, and the incidence in this sector was statistically significant compared with the other occupational groups $(p=0.035$, adjusted for age and gender differences). A detailed analysis of this group revealed that this could be attributed to dairy operators (see lower panel of figure 1), who had an age-standardised and gender-standardised incidence rate of 2.0 (95\% CI 1.2 to 3.0) times higher than the rest of PensionDanmark $(p=0.0071)$. When we analysed the total incidence of all causes of critical illness claims, dairy workers did not differ from the average $(p=0.66)$. Furthermore, we investigated whether the prognosis regarding disability pension after payout due to MS among dairy operators was different from the other occupational groups.
Figure 2 shows that the prognosis was quite similar in the two groups (Log-Rank test $\mathrm{p}=0.96)$.

\section{DISCUSSION}

We used the number of payments of claims for critical illness insurance in a large pension fund to estimate the occupational risks in MS. All diagnoses had been confirmed by a neurologist. PensionDanmark have made a significant effort to find members entitled to payout, and since 2010 all eligible patients have been contacted directly by the pension fund upon diagnosis. The insurance is paid out as a lump sum of 100000 Danish Kroner (approximately 15000 Euro), and there has been much public and press attention to the product throughout the period; thus, it is very likely that all cases have been registered.

Interestingly, dairy operators had the highest risk of developing MS, and the tendency was found both among men and women. We were puzzled by the finding of an increased risk of MS among members of the agricultural segment of the pension fund, because this would seem to go against the vitamin D and sun exposure hypothesis. However, it became clear that dairy operators constituted one-third of this cohort, and this seemed to explain our findings. Importantly, all policies are identical, and all members of PensionDanmark are insured. With regard to the total incidence of critical illness, dairy workers did neither differ from average nor did we observe any differences in the risk of disability.

No previous research has identified an increased risk of MS in dairy operators, so is this a coincidence? Or is it a clue to the aetiology.

Some immunological studies support a linkage between cow's milk and MS. Stefferl et al showed that the milk protein butyrophilin was both capable of inducing and later suppressing demyelinating disease in the animal model of MS, the so-called EAE (the Experimental Autoimmune Encephalomyelitis). The mechanism was probably mediated through molecular mimicry with the myelin oligodendrocyte glycoprotein. ${ }^{9}$

Winer $e t a l^{10}$ reported an abnormal $\mathrm{T}$ cell response to cow's milk proteins in MS and diabetes patients. In MS, the $\mathrm{T}$ cell response was primarily directed towards the epitope Bovine Serum Albumin-193, which was also found to be capable of inducing $\mathrm{MS}$ in the EAE model. ${ }^{10}$ Likewise, Banwell et $a l^{11}$ found an increased response to BSA-193 in children with MS, and demonstrated that $92 \%$ of children with a $\mathrm{T}$ cell response to cow's milk protein also had an autoreactive $\mathrm{T}$ cell response, as opposed to children with no response to milk antigens, among whom only $2 \%$ had an autoimmune $\mathrm{T}$ cell response.

Epidemiology has also suggested in an association between cow's milk and MS. ${ }^{8}$ MS has typically been described as having a North-South gradient, which has been attributed to vitamin D and UV-light exposure. ${ }^{6}$ However, the prevalence of MS not only correlates with latitude but also with national cow's milk consumption. ${ }^{8}$ 


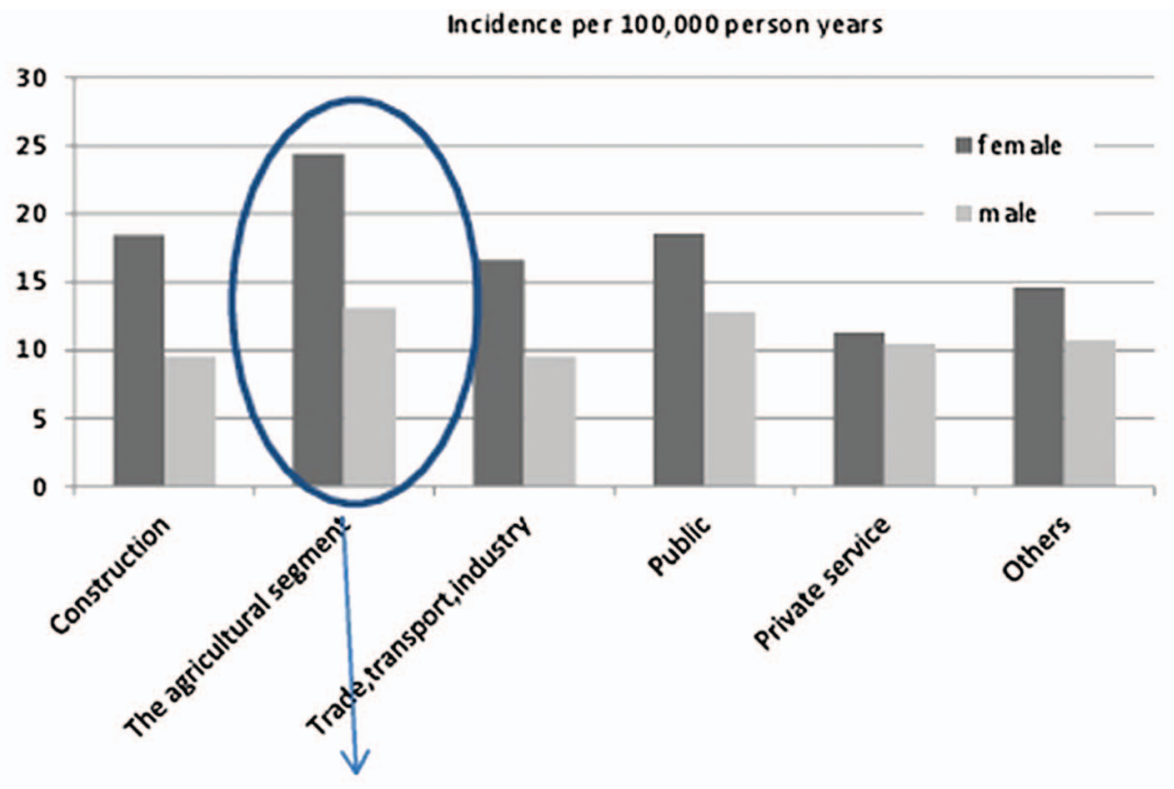

The agricultural segment- subdivision

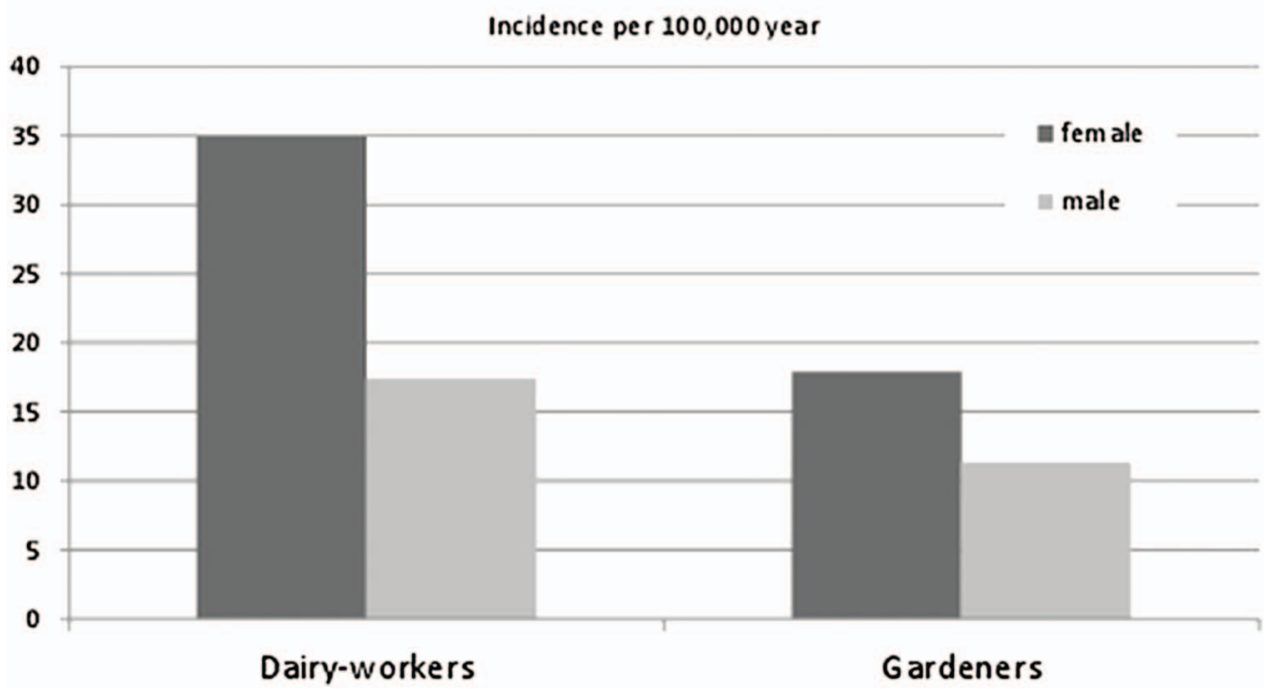

Figure 1 Occupational risks in multiple sclerosis (MS): upper+lower panel: all incidence rates are age standardised with the general age distribution in PensionDanmark. Lower panel: through a total exposure of 83000 person-years in the dairy workers segment we observed 20 cases of MS and in the rest of the agricultural segment 158000 person-years and 21 cases of MS.

The prevalence and incidence of MS is increasing worldwide, and the latitudinal gradient seems to diminish. ${ }^{12}$ Cow's milk is an ubiquitous 'risk factor' in Europe: Danes, for example, drink an average of $92 \mathrm{~L}$ of milk annually $^{13}$ as opposed to a low-risk country such as Japan where cow's milk consumption is around $35 \mathrm{~L}$ per capita. $^{14}$ It has recently been speculated that the increased incidence of MS in the Greek island of Crete could be attributed to a change from goat's milk to cow's milk consumption. ${ }^{15}$

It seems like a fair assumption that dairy operators have a high intake of dairy products and are exposed to bacterial strains from raw cow's milk. This year an Italian group reported that a subspecies of Mycobacterium avium, occasionally found in milk, might be implicated in MS pathogenesis, ${ }^{16}$ and an Australian research team found that women exposed to livestock had an increased risk of developing MS. ${ }^{17}$

\section{LIMITATIONS}

Naturally, occupation does not imply diet and the estimates are still uncertain, and absolute risks are low. An analysis of a subgroup within a subgroup will always increase the risk of a false-positive result. However, this subgroup consisted of all Danish dairy operators in a 10-year period, and we observed 20 cases of MS when only 10 were expected. We have listed some of the reasons why these results should not be regarded as coincidental above. Currently, we have no certain 


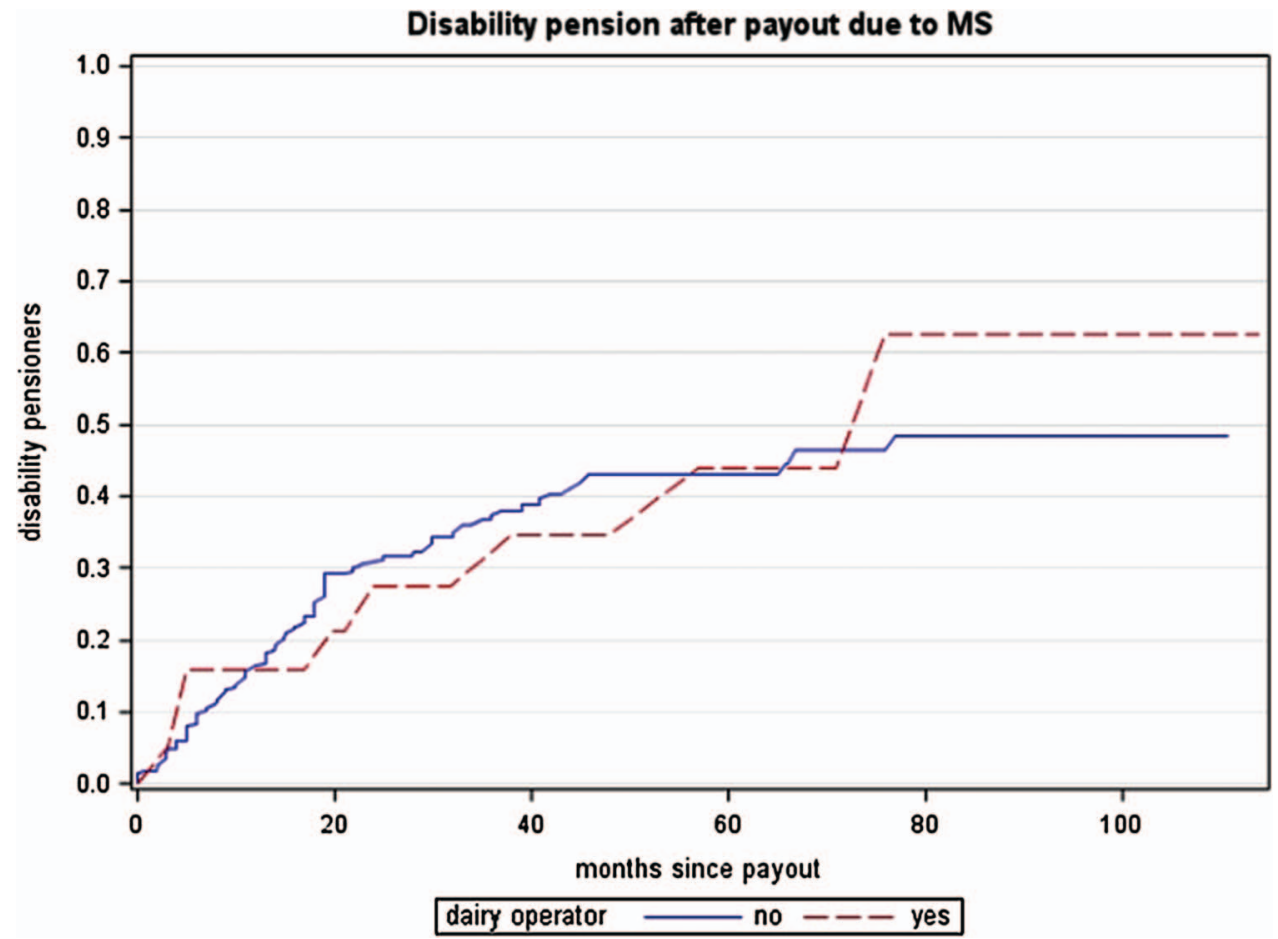

Figure 2 Risk of becoming a disability pensioner. Red line: dairy operators. Blue line: the rest of PensionDanmark with payout due to multiple sclerosis.

explanation of our findings and whether they are due to increased intake of dairy products, the production in itself or simply chance.

Unfortunately, we do not have any personal information like body mass index, smoking, vitamin D status, history of infectious mononucleosis or ethnicity; factors which may potentially affect the risk of MS. ${ }^{6}$ But, the socioeconomic status of these groups is comparable, and we know the general morbidity in the cohort. Thus, a potential confounder such as smoking is unlikely to explain the observed differences. With regard to ethnicity, migration to Denmark has been limited, ${ }^{13}$ and most of the immigrants in Denmark originate from the Middle East. This ethnic group is known to have incidence rates of MS similar to those found in ethnic Danes. $^{18}$

It would have been preferable with a more detailed subdivision of the occupational groups: construction, agricultural and dairy workers are quite specific and uniform groups, whereas the group of occupations in the trade, transport and industry segment of the pension fund is broad and diverse. However, our dataset did not allow for more subtle distinctions, and other occupational risk factors cannot be excluded.

\section{CONCLUSION}

Investigating the number of critical illness insurance payments due to claims relating to specific diseases is a promising tool for disease monitoring and assessment of occupational risks. We found that dairy operators had twice the risk of developing MS compared with the rest of PensionDanmark's members; as previous studies have suggested a linkage between cow's milk and MS, this warrants further investigation.

Acknowledgements We would like to thank the Director of PensionDanmark, Jens-Christian Stougaard, and Deputy Director, Actuary Søren Francis, for allowing us to use the data, and for their inspiring and valuable comments. Thanks to Professor Finn Gyntelberg, MD, for a critical revision of the manuscript. Thanks to Jimmi Østergaard Nielsen for language editing.

Contributors HH was involved in idea and concept, data interpretation, statistical analysis and manuscript writing. BA was involved in idea and concept, data acquisition and interpretation, critical revision of manuscript. EN was involved in idea and concept, general supervision, data interpretation and statistical analysis and critical revision of manuscript.

Funding This research received no specific grant from any funding agency in the public, commercial or not-for-profit sectors.

Competing interests None.

Provenance and peer review Not commissioned; externally peer reviewed.

Data sharing statement No additional data are available.

\section{REFERENCES}

1. Horwitz H. How critical is critical illness? J Insur Med 2009;41:54-61.

2. Mortensen JT, Bronnum-Hansen $\mathrm{H}$, Rasmussen $\mathrm{K}$. Multiple sclerosis and organic solvents. Epidemiology 1998;9:168-71.

3. Riise T, Moen BE, Kyvik KR. Organic solvents and the risk of multiple sclerosis. Epidemiology 2002;13:718-20.

4. Westberg M, Feychting M, Jonsson F, et al. Occupational exposure to UV light and mortality from multiple sclerosis. Am J Ind Med 2009;52:353-7.

5. Freedman DM, Dosemeci M, Alavanja MC. Mortality from multiple sclerosis and exposure to residential and occupational solar radiation: a case-control study based on death certificates. Occup Environ Med 2000;57:418-21. 
6. Handel AE, Giovannoni G, Ebers GC, et al. Environmental factors and their timing in adult-onset multiple sclerosis. Nat Rev Neurol 2010;6:156-66.

7. Butcher PJ. Milk consumption and multiple sclerosis-an etiological hypothesis. Med Hypotheses 1986;19:169-78.

8. Malosse D, Perron H, Sasco A, et al. Correlation between milk and dairy product consumption and multiple sclerosis prevalence: a worldwide study. Neuroepidemiology 1992;11:304-12.

9. Stefferl A, Schubart A, Storch2 M, et al. Butyrophilin, a milk protein, modulates the encephalitogenic $T$ cell response to myelin oligodendrocyte glycoprotein in experimental autoimmune encephalomyelitis. J Immunol 2000;165:2859-65.

10. Winer S, Astsaturov I, Cheung RK, et al. T cells of multiple sclerosis patients target a common environmental peptide that causes encephalitis in mice. J Immunol 2001;166:4751-6.

11. Banwell B, Bar-Or A, Cheung R, et al. Abnormal T-cell reactivities in childhood inflammatory demyelinating disease and type 1 diabetes. Ann Neurol 2008;63:98-111.
12. Koch-Henriksen N, Sorensen PS. The changing demographic pattern of multiple sclerosis epidemiology. Lancet Neurol 2010;9:520-32.

13. Statistics Denmark. 2012

14. Schluep Campo I, Beghin JC. Dairy food consumption, supply, and policy in Japan. Food Policy 2006;31:228-37.

15. Kotzamani D, Panou T, Mastorodemos V, et al. Rising incidence of multiple sclerosis in females associated with urbanization. Neurology 2012;78:1728-35.

16. Frau J, Cossu D, Coghe G, et al. Mycobacterium avium subsp. paratuberculosis and multiple sclerosis in Sardinian patients: epidemiology and clinical features. Mult Scler 2013. [Epub ahead of print].

17. Valery PC, Lucas RM, Williams DB, et al. Occupational exposure and risk of central nervous system demyelination. Am J Epidemiol 2013. [Epub ahead of print].

18. Smestad C, Sandvik L, Holmoy T, et al. Marked differences in prevalence of multiple sclerosis between ethnic groups in Oslo, Norway. J Neurol 2008;255:49-55. 